\title{
FROM CERAMIC CENTRE TO CREATIVE HUB
}

\author{
What the creative hub can teach us about the \\ redevelopment of the Maastricht Sphinx quarter
}

\section{Author: Hanna Hesemans}

Abstract This paper investigates how the concept of the Creative Hub - a space of creativity that fosters knowledge, innovation, and economic growth - can form a positive addition to the creative redevelopment of the former Sphinx factory buildings in Maastricht. The policy of the European Creative Hub Network (2016) is applied to the redesign of the former Sphinx Factory by the municipality of Maastricht. A research method of coding is employed to compare the policy documents of the municipality with those of the Hub Network. It is concluded that the Sphinx could benefit from more community involvement, individual initiative, a bottom up approach, a broader definition of creativity, less focus on regeneration, more flexibility and more inclusiveness. In the end, the findings present an opportunity for moving beyond the debacle of the loss of the cultural capital competition of 2018 . 


\section{Introduction}

"Creative hubs are lighthouses in their neighbourhood" (Apostol, 2016). As spaces where creativity can flourish, hubs are a strategical option to foster knowledge, innovation, and economic growth (Apostol, 2016). In 2016, the British Council launched the European Creative Hub Network, a two-year project that aims at promoting the collaboration and growth of major creative hubs throughout Europe. The project is supported by the European Commission and demonstrates how creative hubs benefit the growth of the creative sector and overall economy (creativehubs.eu, 2016). A creative hub is a "[platform] or [workplace] for artists, musicians, designers, filmmakers, app developers or start-up entrepreneurs" (British Council, n.d., para. 2). The conference Everyone is an Artist,held on September 27 2016, in the Centre Céramique, presented me with the benefits of the hub. At the conference, Roxana Apostel, project leader of the European Creative Hub Network, and Valentina Laterza, director of the hub BASE Milano, gave a vivid plea for the concept. This plea outlined the positive effects hubs could have within their neighbourhoods. Hubs were found to foster creativity, increase economic growth and enrich neighbourhoods (The artist and the others, 2016). The benefits attributed to the hub triggered my imagination.

In 2013, the municipality of Maastricht announced the redevelopment of the former Sphinx factory and the surrounding quarter Belvedère (Derix \& Meys, 2013). Maastricht at this time was competing to become the European Cultural Capital of 2018. Within the context of this competition, it was decided to redevelop the former Sphinx factory terrain as a 'Quartier des arts'. Creative companies would be encouraged to settle in the quarter. The former industrial building site should be transformed into a 'hip' and 'cool' international "Sphinxcene" (Derix \& Meys, 2013, p. 29). The plan matured. In 2016, a cluster of cultural companies houses in the old factory buildings, among them NAIM Bureau Europa, Pathé, the Muziekgieterij, and Lumière. Still, I found that the quarter did not breath an air of all encompassing creativity. The Sphinx quarter seemed a industrial estate, be it one of cultural companies. Imagining alternatives, I wondered: what if the municipality had instead taken the creative hub as starting point for the redevelopment of the Sphinx? In this paper, I investigate the question: How could the concept of the Creative Hub form further develop creativity at the former Sphinx factory site in Maastricht?

Firstly, I aim to shed light on the concept of the hub by a literature review guided by the writings of the Creative Hub Network (British Council, n.d.). After this, I shortly outline the methods employed in my research. Following these methods, I then analyse the policy plans for the Sphinx terrain. The aim of this 
article is to make practical suggestions for the municipality of Maastricht. The municipality should foster community involvement, individual initiative, a bottom up approach, a broader definition of creativity, less focus on regeneration, more flexibility and more inclusiveness. If action is taken with regard to these suggestions, I am convinced that an all-encompassing creativity could soon take hold of the Sphinx quarter. By presenting the municipality with clear guidelines, this article gains its relevance forthe further development of the former Sphinx factory terrain. The paper should be taken as a guideline for the development of a feasible and above all creative Sphinx quarter. This means a Sphinx quarter that is not so much a cluster of cultural companies but a dynamic synthesis of creativity. The creative Sphinx quarter is one that incorporates a broad and inclusive notion of creativity. By setting the tone for a new creative policy in which the hub plays a major role, Maastricht might overcome the debacle of the cultural capital loss of 2018.

\section{Context: from ceramic city to cultural capital}

In 2013, the city of Maastricht radically altered its plans for the development of the former Sphinx factory at the Boschstraat. The Sphinx once was an extolled name in the ceramics industry (De Limburger, 2015). After its closure in 2006, plans were made for the redevelopment of the factory area. In the light of the 2008 financial crisis, the original plan for a modern housing complex was cancelled. Maastricht was at that time still competing to become the European Cultural Capital of 2018. Because of this the ideal of creativity was held dear by the municipality. A plan arose for the redevelopment of the Sphinx factory, and the surrounding quarter Belvedère as a 'Quartier des arts' (Derix \& Meys, 2016). Creative companies were encouraged to settle in the quarter and turn the former industrial buildings into the creative centre of Maastricht. The buildings of the Timmerfabriek, the Eiffel-building, the Landbouwbelang, and the little haven with the Bassin would be part of the redevelopment (Derix \& Meys, 2016). In the European Cultural Capital competition, Maastricht was eventually defeated by the city of Leeuwarden (L1, 2013). Overconfident as Maastricht was, this news came as a bolt from the blue ( $\mathrm{Ll}, 2013)$. Surprisingly, the idea of a Quartier des Arts remained unchanged. In 2017, the Quartier des Arts is getting its envisioned form. The plan for the redevelopment of the Sphinx quarter in a 'Quartier des Arts' has been implemented. The Belvedère is now a cluster of different cultural companies that are related in their cultural content, yet do not share the same mission. For a couple of years, Bureau Europa - a platform for design and archi- 
tecture - and the Muziekgieterij - a live music venue - have taken their places in the former Timmerfabriek. In 2015, the Pathé cinema opened in front of the monumental Eiffel building. In 2016, the Lumière cinema - an art house movie theatre - joined the Timmerfabriek cultural cluster at the side of the Bassin. The Eiffel building is currently being renovated to become a student hotel - with roof terrace (Belvedère Maastricht, n.d.). All initiatives have culture in common, but an overall connection between the cultural enterprises seems to lack. The question that rises is whether there is a way to combine the missions of the enterprises. Is there a way to secure a Sphinx quarter that features all-encompassing creativity rather than loosely coupled cultural enterprises? The hub might light the way.

\section{Literature review: what is a creative hub?}

Due to its flexible nature, the concept of the hub is rather ungraspable. According to the British Council,

"[c]reative hubs are platforms or workplaces for artists, musicians, designers, filmmakers, app developers or start-up entrepreneurs. They are uniquely diverse in structure, sector and services, and range from collective and co-operative, to labs and incubators; and can be static, mobile or online. More importantly, they are drivers in a field with the potential to revive the economy". (British Council, n.d., para. 2)

This definition is to say the least extensive. The hub is defined by uniqueness and diversity, which makes the concept broadly applicable to cultural companies. For people who are not involved with hubs, the question remains: 'which cultural enterprise is a hub, and which is not?'. Such broadness is disruptive in providing a clear basis for research. Therefore, I take the more specific characteristics of hubs mentioned by Tuukka Toivonen and Nicolas Friederici (2015) as leading for my research. Toivonen and Friederici describe the following essential characteristics of the hub:

1 A hub should initiate collaborative communities led by entrepreneurial individuals; at the basis of a hub lays a social milieu wherein collaboration takes place in an egalitarian manner. However, individual agency is prevalent and is thought to benefit the community. Often, hubs facilitate the development of strong individual entrepreneurial positions within communities.

2 A hub should involve diverse members that bring with them heterogeneous knowledge; social inclusion is a precondition. Innovation is thought to happen via 
"creative clashes" (Toivonen et.al., 2015, p. 3) between people with diverse interests.

3 A hub should stimulate creativity in both a physical and digital area; hubs offer opportunities for meeting in a creative environment, face-to-face as well as digital.

4 A hub should localize global business culture; a hub has a bridging function between local policy and international entrepreneurship.

Creative hubs began to develop in the United Kingdom roughly 10 years ago (British Council, n.d.). This development corresponds with the set up of gentrification policies in the 1970s (Rossler, 2011). The ideas that lay behind hubs resonate with early theories of researchers such as Richard Florida. Florida's (2003) Cities and the Creative Class informed the uptake of creative clustering and gentrification in urban policy (Borén \& Young, 2013). In his article, Florida (2003) outlines the creative capital theory. This theory states that creative people are the motors behind economic growth. Creative people tend to inhabit "places that are innovative, diverse and tolerant" (Florida, 2003, p. 8). Florida considers three T's essential for places wanting to attract creative people: Technology, Talent and Tolerance. He moreover emphasizes the importance of place and community, together with face-to-face interaction. He also highlights the tendency for creative companies to cluster in order to "rapidly mobilize talent" (Florida, 2003, p. 5). Hubs follow Florida's theory, in that they are "creative centres" (2003, p.8). Hubs are spaces where creativity can flourish, and they are thought to foster knowledge, innovation and economic growth (Apostol, 2016). Creativity is considered as a driver for the economy, and hubs are often set up in former industrial, now subordinated areas of major cities (British Council, n.d.; Laterza, 2016). The promotion of hubs as initiators of economic growth supports Florida's idea of an economy that is driven by creativity.

Allen J. Scott (2010) takes Florida's theory one step further. He comes closer to the concept of the hub in that his theory is more inclusive and leaves room for paradox. Scott makes a distinction between learning, creativity and innovation. He explicitly emphasizes these three factors as drivers for economic growth. For Scott, talent alone is not sufficient to constitute creative growth. Contrary to Florida (2003), Scott does not omit the paradoxes involved in the cultural field and creative hubs. He describes the importance of maintaining a common ground among hub partners, while at the same time facilitating innovation. Scott moreover emphasizes that clusters that are anchored regionally are not excluded from global creativity schemes. Finally, Scott stresses the paradoxical tendency of creative centres to form a collective community, without letting go of individ- 
uality. What Scott explains is that a hub encompasses characteristics that are often considered uncomplimentary. Hubs "view individuality, leadership, collaboration, and community participation as complementary rather than opposing characteristics" (Toivonen et.al., 2015, p. 3). A certain vagueness is part of their success, it makes them adaptable and therefore sustainable and innovative (Toivonen \& Friederici, 2015).

Hubs, however, are different from gentrification policies in many more ways than Scott (2010) explains. Whereas gentrification often has been imposed topdown, hubs are build bottom-up (Apostol, 2016). Talent is no longer narrowly defined as "those with a bachelor degree and above" (Florida, 2003, p. 10), which consequently leads to a higher standard of inclusivity and openness. Hubs are more flexible than gentrification policies. They are not confined to a fixed set of characteristics such as Florida's three T's or strict policies (Laterza, 2016; Apostol, 2016). Hubs "demand radical change by policymakers" (Borén \& Young, 2013, p. 1801). They feature a new way of social interaction between diverse people. They are in no way the "new creative mainstream" described by Florida (2003, p. 13). Their innovative and flexible nature keeps them from being so.

In this literature review I have touched upon many characteristics and tendencies that lay at the basis of hubs. Yet, I am aware that a certain vagueness concerning hubs might remain, and I think that is part of their strength. Therefore, I would like you to take with you the following words while proceeding with the remaining paragraphs of this essay. A hub can be many things, but "ultimately 'a hub is a hub' when it unites, inspires and promotes a community" (British Council, n.d., para. 5)

\section{Research Methodology}

For my research, I chose to adapt a quantitative approach that enabled me to inspect policy documents in an objective manner. The first part of my research consisted of pre-coding. In setting-up the preliminary coding categories, I looked at Defining what a hub really is by Toivonen and Friederici (2015) and the Creative Hubkit by Matheson (n.d.). These two publications constitute the basis of the European Creative Hubs Network (British Council, n.d.). I made further additions to the preliminary set of codes by investigating my notes on the conference talks of Apostol and Laterza (2016). Then, I compared the codes that resulted from these two steps to the previously outlined literature review. Eventually, I created a list of 15 coding categories. These categories not only give a clear direction to my research. They also sum up the main characteristics that are essen- 
tial for creative hubs. In arbitrary order the categories are: creativity, community, innovation, entrepreneurship, leadership, collaboration, diversity, internationality, support, flexibility, regeneration, bottom-up approach, individuality, place, and inclusiveness (see Table 1).

Broad categories

I. Creativity

2. Community

3. Innovation

4. Entrepreneurship

5. Alternative leadership

6. Collaboration

7. Diversity

8. Internationality

9. Support

10. Flexibility

II. Regeneration

12. Bottom-up approach

13. Individuality

14. Place

15. Inclusiveness

\section{Associated concepts}

creativity enhancement

connect people, shared vision, the collective, social value, communication, engagement with a wider audience novel combinations of ideas and practices, testing new ideas and ventures, research \& development, emerging talents, risk-taking, radical approach, future focused value-creation, start-up revolution, social-entrepreneurship, profitability, finance, investment opportunities, economic growth, income generation

strong network position, distributed leadership, development of leadership skills, people-centred leadership

sharing, networking, peer-to-peer learning, partnerships, knowledge exchange, co-working

creative clashes, heterogeneous cognitive resources, interdisciplinary, working across business sectors, different backgrounds, combination of creative- and non-creative industries, interaction with new and traditional businesses international opportunities, European Creative Hubs Network peer support, provide inspiration, facilitate skills development, offer services and facilities, support for start-ups \& entrepreneurs open ethos, development without structural planning, hybrid business models

public role, positive social and/or environmental impacts, broader impact on local town or city, fulfilment geographic priorities and sector specific objectives, job creation, cultural tourism, set-up in less-well-of area, policy recommendations

not top-down, reciprocal relationship with community, citizen-led, conversation

individual responsibility, self-directed action, loose ties meeting, creativity enhancing interior design, face-to-face contact, online platform, sense of permanence, facilitating regular events, hospitality services

openness, holistic idea of culture, egalitarian participation

Table I Pre-set coding categories and associated concepts 
In the second part of my research, I applied the 15 categories to several publications of the Maastricht municipality. The first publication I inspected was Places for meeting (2012), a report on the municipality's vision for 2030. The second was a more specific ambition plan on the Quartier des Arts: The answer of the Sphinx (Derix \& Meys, 2013). After an analysis of these two publications, I decided to split up the category of entrepreneurship into (1) economic growth and (2) entrepreneurship. I thought this distinction was more useful in understanding the revival of the Sphinx quarter as proposed by the municipality of Maastricht. Moreover, I decided to exclude the notion of leadership and see it as complementary to entrepreneurship, because I found that these terms often overlapped. Finally, I supplemented the associated concepts of the categories. The 15 categories that resulted, together with their related concepts, can be found in below (see table 2).

The final part of my research consisted of applying the final coding categories to the two policy documents written on the redevelopment of the Sphinx, and subsequently analysing the results of this application. I defined areas of similarity and difference between hubs and the Quartier des Arts. Accordingly, I investigated what positive additions the creative hub could bring to the redevelopment of the Sphinx quarter. The results of this final research step are described in the following paragraphs of this paper.

\section{Analysis}

The following part of this research concerns my analysis of the Maastricht municipality's policies on the creative redevelopment of the Sphinx quarter. After describing the results of coding, I will discuss these results. Finally, I outline five policy implications that should be taken as guidelines for the further development of the former Sphinx factory terrain. A terrain that should become the creative hub of Maastricht.

\section{I Results}

The results of my study show that all 15 coding categories are somewhere mentioned in the 2030 vision of the Maastricht municipality (2012). In The answer of the Sphinx (Derix \& Meys, 2013) most categories are mentioned. In the latter, individuality and inclusiveness are not mentioned. Community is only touched upon once (Table 3). 
Broad categories

I. Creativity

2. Community

3. Innovation

4. Entrepreneurship

5. Economic growth

6. Collaboration

7. Diversity

8. Internationality

9. Support

10. Flexibility

II. Regeneration

12. Bottom-up approach

13. Individuality

14. Place

15. Inclusiveness

\section{Associated concepts}

creativity enhancement, growth of creative industry, crafts connect people, shared vision, the collective, social value, communication, engagement with a wider audience, the local novel combinations of ideas and practices, testing new ideas and ventures, research \& development, emerging talents, risk-taking, radical approach, future focused, knowledge-economy, the 'modern', new urbanism

start-up revolution, social-entrepreneurship, freelancing, independent-contractors, private initiatives, alternative entrepreneurship

value-creation, profitability, finance, investment opportunities, income generation, career opportunities, augmenting the job market, business competitiveness, establishment of businesses, economic vitality

sharing, networking, peer-to-peer learning, partnerships, knowledge exchange, co-working, clustering, cross-border cooperation, publicprivate collaboration

creative clashes, heterogeneous cognitive resources, interdisciplinary, working across business sectors, different backgrounds, combination of creative- and non-creative industries, interaction with new and traditional businesses, multifunctionality, differentiation of supply International opportunities, European Creative Hubs Network, international positioning of the city, international workers, 'Euregio' (region of Europe)

peer support, provide inspiration, facilitate skills development, offer services and facilities, support for start-ups and entrepreneurs, education, facilitate development of awareness, create work spaces open ethos, development without structural planning, hybrid business models, all-encompassing definition, no set endpoint, alternative/flexible working, flexible engineering, temporal functions, dynamic character public role, positive social and/or environmental impacts, broader impact on local town or city, fulfilment geographic priorities and sector specific objectives, job creation, cultural tourism, set-up in less-well-of area, policy recommendations, creativity leads to economic growth, the young/hip/cool/bohemian/talented as drivers for prosperity, area-attractiveness, vitalisation of city's scenery Not top-down, reciprocal relationship with community, citizen-led, conversation/dialogue, demand-oriented policy, participation, individual responsibility, self-directed action, loose ties, independency meeting, creativity enhancing interior design, face-to-face contact, online platform, sense of permanence, facilitating regular events, hospitality services, virtual environment openness, holistic idea of culture, egalitarian participation, reducing social exclusion, preventing segregation, making room for different lifestyles and niches 


\begin{tabular}{|c|c|c|c|c|c|c|}
\hline Broad categories & Sphinx & $\begin{array}{l}\text { Overall } \\
\text { Policy }\end{array}$ & Total & $\begin{array}{l}\text { Percentage } \\
\text { Sphinx }\end{array}$ & $\begin{array}{c}\text { Percentage } \\
\text { Overall } \\
\text { Policy }\end{array}$ & $\begin{array}{c}\text { Percentage } \\
T\end{array}$ \\
\hline I. Creativity & II & 9 & 20 & $10,0 \%$ & $3,0 \%$ & $5,0 \%$ \\
\hline 2. Community & I & 20 & 21 & $\mathrm{I}, 0 \%$ & $7,0 \%$ & $5,5 \%$ \\
\hline 3. Innovation & 20 & 28 & 48 & $19,0 \%$ & $9,5 \%$ & $12,0 \%$ \\
\hline 4. Entrepreneurship & 5 & 17 & 22 & $4,5 \%$ & $6,0 \%$ & $5,5 \%$ \\
\hline 5. Economic growth & 8 & 22 & 30 & $7,5 \%$ & $7,5 \%$ & $7,5 \%$ \\
\hline 6. Collaboration & 5 & 23 & 28 & $4,5 \%$ & $8,0 \%$ & $7,0 \%$ \\
\hline 7. Diversity & 11 & 11 & 22 & $10,0 \%$ & $4,0 \%$ & $5,5 \%$ \\
\hline 8. Internationality & 7 & 10 & 17 & $6,5 \%$ & $3,5 \%$ & $4,5 \%$ \\
\hline 9. Support & 4 & 25 & 29 & $4,0 \%$ & $8,5 \%$ & $7,5 \%$ \\
\hline 10. Flexibility & 7 & 22 & 29 & $6,5 \%$ & $7,5 \%$ & $7,5 \%$ \\
\hline II. Regeneration & 20 & 37 & 57 & $19,0 \%$ & $13,0 \%$ & $14,5 \%$ \\
\hline $\begin{array}{l}\text { 12. Bottom-up } \\
\text { approach }\end{array}$ & 3 & 10 & 13 & $3,0 \%$ & $3,5 \%$ & $3,5 \%$ \\
\hline I3. Individuality & 0 & 7 & 7 & $0,0 \%$ & $2,5 \%$ & $2,0 \%$ \\
\hline 14. Place & 5 & 42 & 47 & $4,5 \%$ & $14,5 \%$ & $12,0 \%$ \\
\hline 15. Inclusiveness & 0 & 6 & 6 & $0,0 \%$ & $2,0 \%$ & $1,5 \%$ \\
\hline Total & 107 & 289 & 396 & & & \\
\hline
\end{tabular}

Table 3 Results of coding - The Answer of The Sphinx (2013) \& Vision for 2030: Places for Meeting (20I2)

In total, I found 107 terms in the Sphinx report (Derix \& Meys, 2013). I found 289 hits within the document on the overall strategy for Maastricht 2030 (2012). This adds up to 400 terms that can be related to the concept of the hub insofar a hub is: creativity, community, innovation, entrepreneurship, economic growth, collaboration, diversity, internationality, support, flexibility, regeneration, bottom-up approach, individuality, place, and inclusiveness. Evident from the results is also that the municipality places most emphasis on the concept of regeneration (14,5\%). Following at a second place is 'place' (12,0\%). The latter results from a high number of counts in the 2030 vision. 'Place' is only mentioned 5 times in The answer of the Sphinx. In general, less attention is given to inclusiveness $(1,5 \%)$ and individuality $(2,0 \%)$. Economic growth has a similar percentage of mentionings in both documents (7,5\%). A visual overview of the results can be found in Figure 1. The graph is shows that overall, the foci of the two policy documents are similar. Innovation is highly valued, as well as regeneration. Economic growth, and place show little peeks.

What is important is that creativity is only valued highly in the Sphinx document. For diversity, the Sphinx ambition plan also has a relatively higher count. What is neither visible from the table nor from the graph is the mentioning of 
terms that are not necessarily related to hubs, yet still important to the municipality of Maastricht. Both documents place sustainability, a green environment, and climate neutrality at their core. Accessibility of the city centre and services is another important point. Finally, the aim of Maastricht to become cultural capital in 2018 - in 2013 still actual - is frequently mentioned (Gemeente Maastricht, 2012; Derix\&Meys, 2013)

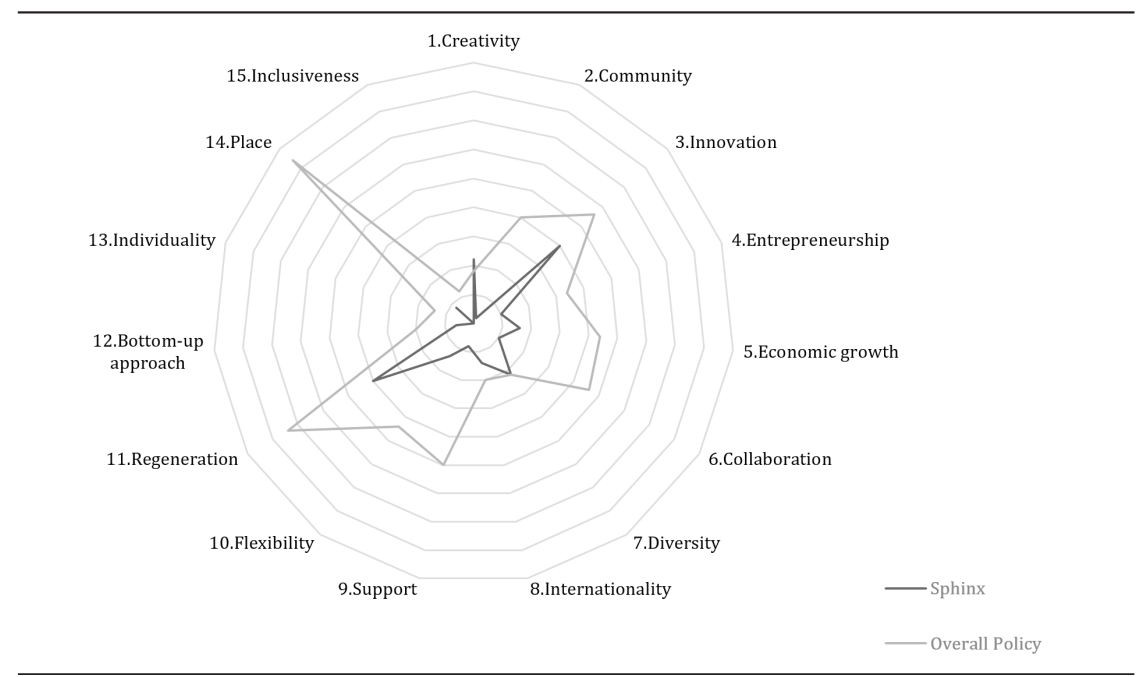

Figure I Visual representation of results - The Answer of The Sphinx (20I3) \& Vision for 2030: Places for Meeting (2012)

\subsection{Discussion}

Both the Creative Hubs Network and the municipality of Maastricht hope to foster creativity (Derix \& Meys, 2013; creativehubs.eu, 2016). This creativity is mostly mentioned in the ambition plan for the Sphinx. The term is less mentioned in the municipality's vision for 2030 (Table 3). Because of this, the Belvedère establishes itself as a cultural centre, making the case for my application of the hub to this quarter of Maastricht. The results of my analysis further support this view. They show similarities between the policy ideals of the Maastricht municipality and those of the European Creative Hubs Network. These similarities illustrate how the concept of the hub could be used in the pursue of policy ideals within the redevelopment of the Sphinx quarter. The similarities also illustrate how the hub could be used to explain steps already taken in the process of redevelopment. 
Many of the tensions found within hubs are mentioned in the vision document for Maastricht (Gemeente Maastricht, 2012): for instance, the tension between the collective and the individual, or the tension between the local and the international. Furthermore, Maastricht aims, in line with the ideals of hubs, at innovation by "cross-sectorial benefits" (Gemeente Maastricht, 2012, p. 64) and a clash of interests. Maastricht aims at diversity of its facilities by combining multiple services at one location. Moreover, support to learning and entrepreneurship - especially starters and freelancers - is considered important for facilitating innovation (Gemeente Maastricht, 2012). In this light, new forms of (social) entrepreneurship and flexible working are promoted. A further similarity arises from the "international standards" (2012, p. 65) that the municipality adheres. These standards echo the international nature of the hub network. Finally, flexibility is also aimed for in both the hub and the redevelopment of the Sphinx. Maastricht does this by means of temporal functions, for instance: temporary nature concepts such as the Sphinx park (Derix \& Meys, 2013, p. 23).

Although the Quartier des Arts resembles the hub at some points, there are differences that my analysis highlights. The hub has characteristics that are not present (yet) in the plans for the redevelopment of the Sphinx. I am convinced that these differences show points of improvement for the creative redevelopment of the Sphinx factory site. My points of improvement consider policy issues from the Maastricht 2030 vision that could be implemented in the Quartier des Arts but are not implemented yet. Furthermore, they consider what 'never-mentioned' values 'hubbing' could bring to the Sphinx quarter.

First, some values that are inherent in both the overall policy of the municipality (2012) and hubs are omitted in the redevelopment of the Sphinx. Community, inclusiveness and individuality play no role in the Sphinx ambition plan, whereas they feature in the municipality's vision for 2030 (2013). In The answer of the Sphinx (Derix \& Meys, 2013) the municipality expresses the desire for "an active role in the planning" (Derix \& Meys, 2013, p. 35) that concerns the former Sphinx. Partners are said to join along the way (Derix \& Meys, 2013). Contrary to this view, the hub suggests the importance of having a community before even starting (Apostol, 2016). The value given to community building is so essential that there are even moving hubs without a physical 'home' (Matheson \& Easson, n.d.). The hub concerns a bottom-up process in which individual actors play a great role. The first step in creating a hub is building up a community of individuals. If community building is done right, inclusiveness is part of the hub's outcomes (Toivonen \& Friederici, 2014). The ideals in the vision of 2030 underscribe the community, individuality and inclusivity notions that play such great role in hubs (Toivonen \& Friederici, 2014; Matheson \& Easson, n.d.). I am 
convinced that it would be a good thing to further these ideals within the former Sphinx area. The Sphinx could benefit from a more bottom-up approach in which the community of Maastricht is consulted without there being plans beforehand. Above all this would lead to a greater support and participation by individuals, and more inclusiveness. The hub has the potential to further the policies of Places for meeting (2012) within the Sphinx Quarter. A hub-outlook would positively add to the successful development of the creative vision on the Sphinx in three aspects: community, inclusiveness, and individuality.

Yet, I think that the hub can bring more to the Quartier des Arts than policies underscribe, because the hub presents several challenges for the strategic policies of the Maastricht municipality (2012). Firstly, hubs direct towards a broader view on creativity. In the documents of the municipality, the term 'creativity' is used as encompassing culture, i.e., arts and crafts, music and theatre (Gemeente Maastricht, 2012; Derix \& Meys, 2013). In hubs, creativity can be nearly everything that goes beyond mere reproduction. Creativity signifies all forces that lead to innovation, be it technological or cultural, or even scientific (creativehubs.eu, 2016). Secondly, it should be noted that hubs are fundamentally different from clusters. Clusters are companies within one terrain, such as is currently the case within the Sphinx quarter, where Pathé, Lumière, Muziekgieterij, and Bureau Europa reside within the former factories. A cluster does not mean collaboration. The companies that are currently housed on the former factory terrain are separate entities. They have their own missions, which might be contesting. Sometimes they are competitors, as is the case with cinema's Lumière and Pathé. In contrary to a cluster, a hub is one organisation, with one mission (creativehubs.eu, 2016). In a hub, there is a common good, something to fight for together. This common good makes that resources and knowledge are shared more easily. Furthermore, face-to-face contact is simply facilitated. Finally, innovations happens faster. The Maastricht municipality focuses on innovation (2012). Therefore, transforming the Quartier des Arts from a cluster to a hub might be a fruitful development.

Finally, I would like to draw your attention to the spacious consideration of regeneration in the policy plans by the Maastricht municipality. Regeneration, or gentrification, is severely criticised. As showed in my literature review, the ideals of the hub are in line with this criticism. Aiming to be "the bohemian, cool and hip" (Derix \& Meys, 2013, p. 29) will not make your city inclusive. Talent in the sense of a degree - knowledge economy - will not necessarily bring creativity and innovation (Rossler, 2011). The values underlying gentrification are very exclusive. The bohemian, cool, and hip have become the standard in a world in which the upper classes are bohemians themselves (Rossler, 2011). Letting go 
of the ideal of economic growth as a result of creativity is hard, but necessary. The success of hubs shows that a focus on community - an inclusive one - and a sense of broad creativity foster innovation. In the long term this might result in economic growth; yet, this should not be the focus. This is what the hub prescribes (creativehubs.eu, 2017). Filling in the gaps of a "concept that remains unaltered" (Derix \& Meys, 2013, p. 33) is unfortunately only a small step in letting go the idea of top-down gentrification that is so popularised in our society. Flexibility, named as a "key concept" in the municipality's vision for 2030, will not result from a pre-set idea or concept, nor from the guidelines of gentrification once prescribed by theorists such as Florida. Instead, innovative hubs "demand radical change by policymakers" (Borén \& Young, 2013, p. 1801).

\subsection{Policy implications}

Ideally, the values outlined above would have been embraced earlier in the development of the Sphinx area. Unfortunately, this is not the case. The ambition plan of 2013 has witnessed its implementation. The Sphinx quarter currently is a cluster of creative companies. It is not a hub. Fortunately, there is a lot we - the municipality and its citizens - can do to create a more hub-like cluster of Sphinx companies. In this light, I would like to make the following suggestions:

1 We should try to make sure that the community of Maastricht initiates further developments within the Sphinx quarter. Community building is something that should come prior to all further steps that are taken. A suggestion would be to organise a collective brainstorm and develop plans accordingly. Primarily, we should insist that we reach a diverse audience with great communication.

2 We should aim to align the missions of the companies within the Sphinx cluster. This can be done by initiating fruitful collaboration and mutual interdependency between Pathé, Lumière, the Muziekgieterij and Bureau Europa. An idea would be to organise a yearly 'Sphinx festival'.

3 We should dare to let go of the control. This notion is related to the first suggestion. Citizen-led initiatives should be encouraged within the Sphinx quarter. This can be done by loosening the regulations surrounding permits for events. If a flexible environment is what you desire, you should be flexible yourself.

4 We should redefine creativity. Creativity is not necessarily cultural. Innovative enterprises or unexpected collaborations might make for very creative outcomes. It is important to take on a broad notion of creativity. For instance, by including non-cultural businesses within the creative centre of the Sphinx. 
5 We should focus on innovation and community rather than economic growth by regeneration. This might be hardest to implement. It is also most costly. Think of supporting start-ups with great ideas, even if not profitable on the short-term. Or, support innovative concepts/events, even if they risk monetary failure. In the end, these initiatives will pay off. Yet, we should be careful not to make this our short-term goal.

\section{Limitations}

Some limitations to my research are important to highlight. Further research will be needed in order to establish a more complete vision on the ways in which the cultural hub can bring success to the further development of the former Sphinx. Policy documents are a good first step, but they eventually need to be complemented with other data.

A second limitation arises from the concept of the hub itself. The hub is presented as an ideal case in this paper, but I am aware that there are challenges to the concept. Often, financing hubs is a problem. Moreover, a hub's placement in an industrial area can undermine it from reaching the many. Furthermore, diversity is an ideal that is difficult to fulfil in a society where the creative is still very much the smart (Laterza, 2016). Finally, hubs are symptomatic for the art world. Balancing non-profit and profit interests is complicated. Next to this, hubs have broader societal goals that are not easily measured.

Another limitation has been noted earlier. The Sphinx quarter is no longer an empty factory. In 2016, several cultural companies have settled here. To come to full maturity, a hub should have been initiated earlier in the process. Nevertheless, I think that aiming for a more hub-like cluster of companies worthy and feasible step to take.

Finally, I must admit that hubs will not solve every possible challenge of the municipality. While hubs encompass multiple dimensions, this is not to say that they encompass everything. Accessibility for instance, one of the policy aims of the municipality of Maastricht (2012), will not be improved by the transformation of the Sphinx cluster in a hub. Neither does a hub necessarily lead to a more sustainable environment. Moreover, the hub will not reverse history and instantly transform Maastricht into the cultural capital of Europe. 


\section{Conclusion}

Despite the limitations of my research, I am convinced that the concept of the hub can bring valuable additions to the Sphinx cultural center. Every strategy will have its disadvantages, and it is important to weigh them carefully and to investigate what is to be gained from them. The Sphinx quarter can benefit from a more hub-like development in several ways. Transforming the current cluster of companies in a hub will initiate a development towards more flexibility, a broader approach to creativity, and finally: faster innovation. Steps the municipality can take to foster these developments are: (1) making sure that the community of Maastricht initiates further developments within the Sphinx, (2) aligning the missions of the companies within the Sphinx cluster, (3) daring to let go of the control, (4) redefining creativity and (5) focusing on innovation and community rather than economic growth by regeneration. Above all, the presented study should be an encouragement for the city of Maastricht. Hubs might lighten up our view on the Maastricht debacle of the European Cultural Capital of 2018. We have dwelled too long on policies that were developed for it. The Quartier des Arts is one of these. As a city, however, we should look forward. We have to move on. The hub presents a new structural direction for fostering creativity in the city that might bring inspiration and a new focus to our cultural policy. Let us take the leap. Maastricht, start hubbing.

\section{References}

Apostol, R. (2016, September). British Council: European Network of Creative Hubs. Presentation at the conference Everyone is an Artist, Maastricht.

Belvedère Maastricht (n.d.). Social updates. Retrieved from http://www.belvedere-maastricht.nl/

Borén, T. \& Young, C. (2013). Creative with the 'Creative City'? Towards new perspectives on creativity in urban policy. International Journal of Urban and Regional Research, 37(5), 1799-1815. doi:10.1111/j.1468-2427.2012.01132.x

British Council. (n.d.). European Creative Hubs Network. Retrieved from http://creativehubs.eu/ about-european-creative-hubs-network

De Limburger. (2015, July 17). Laatste restje van Sphinx weg uit Maastricht. Retrieved from https:// www.1limburg.nl/laatste-restje-van-sphinx-weg-uit-maastricht

Derix, G. \& Meys, W. (2013). Het antwoord van de Sphinx: ambitiedocument herijking programma Belvedère [The answer of the Sphinx]. Maastricht: Gemeente Maastricht. Retrieved from http:// www.belvedere-maastricht.nl/wp-content/uploads/2013/10/@-Definitief-Boekje-Ambitie-document-Belvedere-2012-A5kl.pdf 
Florida, R. (2003). Cities and the creative class. City \& Community, 2(1), 3-19. doi: 10.1111/15406040.00034

Gemeente Maastricht. (2012). Structuurvisie Maastricht 2030: Ruimte voor Ontmoeting II [Vision for 2030: Places for Meeting]. Retrieved from https:/www.gemeentemaastricht.nl/fileadmin/files/ GeMa/Doc/00_Algemeen/Structuurvisie_Maastricht_2030_Deel_II_29_mei_2012.pdf

Hoogen, Q. van den (2016, September). Cultural policy research. Lecture for the course Arts Policy \& Politics, Faculty of Arts and Social Sciences, Maastricht.

L1. (2013). Organisatie Maastricht Culturele Hoofdstad 2018: Heel erg jammer. Retrieved from https:// 11.nl/organisatie-maastricht-culturele-hoofdstad-2018-heel-erg-jammer-34219

Laterza, V. (2016, September). Base Milano. Presentation at the conference Everyone is an Artist, Maastricht.

Matheson J. \& Easson, G. (n.d.). Creative HubKit. Edinburgh/Dundee: British Council. Retrieved from http://www.creativeconomy.britishcouncil.org

Rossler, M. (2011). Culture Class: Art, Creativity, Urbanism, part I. Retrieved from http://www.eflux.com/journal/culture-class-art-creativity-urbanism-part-i/

Scott, A.J. (2010). Cultural economy and the creative field of the city. Geografiska Annaler: Series B, Human Geography, 92(2), 115-130. doi: 10.1111/j.1468-0467.2010.00337.x

Toivonen, T., \& Friederici, N. (2015). Time to define what a "hub" really is. Retrieved from Stanford Social Innovation Review: https://ssir.org/articles/entry/time_to_define_what_a_hub_really_is 